\title{
Study of Adolescents' Introversion-Extraversion Traits, Need for Belongingness and Indulgence in Social Networking
}

\author{
Ruchi Dubey Chaturvedi ${ }^{1}$ \\ Aneesha Munshi \\ Vani Singla ${ }^{3}$ \\ Naina Shahri ${ }^{4}$ \\ Simantika Chanchani ${ }^{5}$ \\ ${ }^{1}$ Asst. Professor, Department of Psychology, Jaihind College, Mumbai. \\ 2,3,4,5Student Member, Psychology Association, Department of Psychology, Jaihind College, \\ Mumbai. \\ E-mail-ruchidc1@gmail.com
}

\section{ABSTRACT}

The present study was undertaken on undergraduate adolescents to gain an insight into the relationship between Introversion-Extraversion, Social Networking Intensity and Need for Belongingness. In order to measure the Social Networking Intensity, the amount of usage of Facebook was measured, since it is the most widely used social networking website. To study these variables purposive sampling was done taking 100 undergraduate students. Questionnaires were administered which gavemeasures on adolescents' Need for Belongingness, Social Networking Intensity and Introversion, Extraversion trait. The results showed that the adolescents were moderate in their Need for Belongingness. In terms of Introversion-Extraversion they were again moderately placed there by implying that this trait was changing according to contextual factors. Further, they also exhibited only moderate need to indulge in Social Networking. The correlation measures between Social Networking Intensity with IntroversionExtroversion and Need to Belongingness were moderate yet significant. It implies that to some extent social networking intensity is getting influenced by Need for Belongingness and Introversion-Extroversion. $t$-test value showed that only the trait of Need for Belongingness and Social Networking Intensity differed significantly from each other. This implies that as the participants Need for Belongingness was situational bound, so was their need to access Social Networking sites. It also indicates that the adolescent would be more keen to establish a closer face-to-face interaction and relationship. The $t$ test value between Introversion-Extraversion and Need for Belongingness was not significant. Also, Need for Belongingness did not differ significantly from Social Networking Intensity as indicated by the $t$ test. This study refutes the popular belief that current adolescents are highly dependent on Social Networking to satisfy their Need for Belongingness and Affiliation. It also, questions the notion that due to peer pressure most adolescents are forced to become extroverts.

Key words: extraversion, introversion, affiliation, belongingness, social networking, adolescents, communication. 


\section{INTRODUCTION}

Adolescence is a revolutionary period in human life, involving major changes in physical, mental, emotional and especially social aspects of an individual's life. It is that period when one is full of energy, ambitions and zest for life. The power possessed by youth is a recognized force today. There is a high need for affiliation present in all adolescents due to which they use Social Networking sites. These sites offer an easy and quick way to satisfy their need for belongingness. In the $21^{\text {st }}$ century, people communicate by sending a text message from their mobile phone, post comments on their favorite online networking site or send a short tweet. Regardless of being an extrovert or an introvert, the youth today, use Social Networking sites for their day-to-day interactions. The Social Networking mode of communication might be making people extroverts [1].

Social Networking sites are defined as web-based services that allow individuals to construct a public or semi-public profile within a bounded system, articulate a list of other users with whom they share a connection, and view and traverse their list of connections and those made by others within the system [2]. There are many types of Social Networking sites, which serve different kinds of purposes. Few of the famous ones are blog, e-mail, instant messaging, and video conferencing. This can result in connections between individuals [3]. The most popular social networking website among the adolescents today is Facebook.

The Need for Affiliation is one of three acquired needs laid out by psychologist David McClelland in his theory on social motives governing human behavior. This particular need concerns the desire to be associated with specific people and groups, to have a greater sense of belonging and place. It can play a role in a variety of human interactions and in the formation of bonds and friendships. McClelland's theory is of particular interest to the management and business community, where understanding motivations can be important for handling personnel [4].

A person with high Need for Affiliation tends to want to belong to groups, create connections, and establish relationships with other people. In a setting like an office, this might include joining office organizations, making friends with coworkers, and creating a sense of belongingness within the company. Social Networking has significantly changed the way we now satisfy our Need of Affiliation. People in a society now-a-days connect with one another, do business, and socialize using Social Networking sites.

A person exhibiting low Need of Affiliation can be considered to having a more independent personality. He/she does not feel a strong desire to affiliate with others and may be viewed as loners, and could have difficulty finding social support. Today's youth is assumed to having high Need for Affiliation and Belongingness. Eysenck proposed a theory on Physiology and Genetics. He stated that personality differences emerge out of our genetic inheritance. Further, all human traits can be broken down into two different categories: Neuroticism and Introversion-Extraversion. Neuroticism personality trait ranges from being sometimes calm to being very nervous. This make the people develop neurotic disorders later in life when faced with excess uncontrollable stresses [5].

Extraversion-Introversion, a term means a range of trait going fromshy or quiet people versus out-going or loud people. Extraversion types of personalities need a lot of stimulation and often express emotions freely in inter personal 
relationships. Extraversion lacks symptoms of repression, conflict, over-sensitiveness, creating unrealistic goals and day dreaming. They are usually relaxed and very confident. In contrast, Introversion personality types need little external stimulation. They focus more on their inner feelings and bottle them up. They do explode if they are pushed too far. An extremely introverted person obtains his satisfactions by mental imagery [6].

Nicole Lehmann suggested that Introverts are less likely to use Facebook relative to Extroverts. Introverts in contrast are more likely to use the private message function, they are less likely to post on other people's walls, and they have fewer total Facebook friends [7]. It has been found that individuals that have a higher level of Extraversion belonged to more Facebook groups. Contradicting this, anotherresearch has found that there is no relationship between the number of Facebook groups a person has and Introversion- Extraversion traits.Further there are more conflicting view points about whether or not Social Networking Sites (SNS) detracts from face-to-face relationships.Some researches do indicate that SNS does not show a negative effect on face-to-face relationship [8].

Another research based on this topic suggested that users of Facebook tend to be more Extroverted individuals. This is because these Extroverts constantly seek interaction with others. And SNS offers the Extroverts the ability and platform for which they can maintain and also create relationships with others. In other words, the Internet is an extension to the extroverts' interaction with the outside world. Contrary to this, other researches have shown that SNS also fulfills the needs of the Introverts because they enjoyinteracting with people online just as much as the Extroverts [9].

\section{METHODOLOGY}

The aim of the research was to study the impact of IntroversionExtraversion and Need for belongingness on adolescents' usage of Social Networking

\section{Hypothesis}

Adolescents will be high in accessing Social Networking sites, high in Need for Belongingness, in the Introversion-Extraversion continuum the participants would be predisposed towards Extraversion, participants with high Extraversion and Need for Belongingness will access Social Networking sites more.

A purposive sample of 100 Under-Graduate students was selected.

The purpose was to investigate the relationship between Introversion-Extraversion, Social Networking intensity and Need to Belongingness in the adolescents. A random group design was used.

\section{Tools Used}

1. Facebook Intensity Scale [10] (alpha $=0.80)$

2. Introversion and Extraversion scale [11] (alpha>0.80)

3. Need to Belongingness Scale [12] (Alpha=0.81)

All the three scales mentioned above were administered to the entire sample. 


\section{RESULTS}

Table 1- Mean scores Social Network Intensity (SNI), Introversion-Extraversion (IE) and Need To Belongingness (NTB) scores of the youth $(\mathrm{N}=100)$

\begin{tabular}{|ccccc|}
\hline Variables & N & Mean & SD & Level \\
\hline $\begin{array}{c}\text { Social Networking } \\
\text { intensity }\end{array}$ & 100 & 41.9 & 10.62 & Moderate \\
\hline $\begin{array}{c}\text { Introversion } \\
\text { Extraversion }\end{array}$ & 100 & 38.27 & 6.680 & Moderate \\
\hline Need to Belongingness & 100 & 32.94 & 6.53 & Moderate \\
\hline
\end{tabular}

As observed from Table 1, the mean scores of all three variables i.e., Social Networking, Introversion Extraversion and Need to Belongingness fall in the moderate range. The youth of today, is not over indulging in Social Networking. He is moderate even in his Need for Belongingness and Affiliation. The youth is also able to strike a balance between Introversion-Extraversion traits.

Table 2 - Mean scores and comparison between two variables:Social Networking Intensity (SNI) and Introversion - Extraversion (IE) ( $N=100)$

\begin{tabular}{|cccccc|}
\hline Variables & N & Mean & SD & df & t value \\
\hline $\begin{array}{c}\text { Social Networking } \\
\text { Intensity }\end{array}$ & 100 & 41.9 & 10.62 & 99 & NS \\
\hline $\begin{array}{c}\text { Introversion } \\
\text { Extraversion }\end{array}$ & 100 & 38.27 & 6.68 & & NS \\
\hline
\end{tabular}

NS- Not significant

As observed from Table 2, the trait of Introversion-Extraversion is independent of the need to access Social Networkingsites. The adolescents while exhibiting Introversion-Extraversion traits are able to maintain a correct balance between them. They also are able to access Social Networking sites when the need arises, irrespective of their basic personality traits.

As observed in Table 3, there lies a significant difference between Introversion-Extraversion and Need to Belongingness. Both these traits exist at moderate levels in the adolescent participants, thereby implying a balanced approach. There might be many other personality traits which intervene between these two variables under study. 
Table 3 - Mean scores and comparison between two variables: Introversion Extraversion (IE) and Need To Belongingness (NTB) $(\mathbf{N}=100)$

\begin{tabular}{|cccccc|}
\hline Variables & N & Mean & SD & df & t value \\
\hline $\begin{array}{l}\text { Introversion } \\
\text { Extraversion }\end{array}$ & 100 & 38.27 & 6.68 & 99 & $1.03 *$ \\
\hline $\begin{array}{c}\text { Need to } \\
\text { Belongingness }\end{array}$ & 100 & 32.94 & 6.53 & & $\mathrm{P}<0.025$ \\
*significant & & & & & \\
\hline
\end{tabular}

Table 4 - Mean scores and comparison Social Networking Intensity and Need to Belongingness (NTB) $(\mathbf{N}=\mathbf{1 0 0})$

\begin{tabular}{|cccccc|}
\hline Variables & N & Mean & SD & df & $\begin{array}{c}\mathbf{t} \\
\text { value }\end{array}$ \\
\hline $\begin{array}{c}\text { Social Networking } \\
\text { intensity }\end{array}$ & 100 & 41.9 & 10.62 & 99 & $3.46^{* *}$ \\
\hline Need to Belongingness & 100 & 32.94 & 6.53 & $\begin{array}{c}\mathbf{p < 0 . 0 0 5} \\
\text { significant }\end{array}$ \\
\hline
\end{tabular}

As observed in Table 4, the two variables under study differ significantly from each other. As the participants have moderate need to belongingness, it might be getting satisfied by face-to-face personal contacts. This might be leading them to access Social Networking sites only to an optimal level.

Correlation analysis indicates that there is a relationship between the Social Network intensity and Need To Belong. This relationship though being moderate, is significant $(r=0.230, p=0.02)$. Related to this a slightly weaker relationship exists between Social Networking Intensity and Introversion-Extraversion. However, this correlational relationship is also significant $(r=0.22, p<0.05)$. For the participants, there does seem to be some interaction between the three variables i.e., Social Networking Intensity, Need for Belongingness and Introversion-Extraversion.

\section{DISCUSSION}

The adolescent participants of this study emerge as matured and controlled individuals. They are able to maintain harmony between their IntroversionExtroversion traits. As regarding their Need for Belongingness, it seems to be getting satisfied through more meaningful face to face interactions. This is the reason why they are not over indulging in exploiting social networking sites.

Among the adolescents of this study there was a moderate and significant relationship with need for belongingness and Introversion-Extraversion. There may be additional factors which could be increasing vulnerability for accessing social 
networking sites in other people. The difference between Social Networking Intensity and Introversion-Extroversion is not significant which means that the intensity of networking does not differ significantly from Introversion-Extroversion trait. This implies the probability of many other intertwining personality traits between these two variables. The $t$ test value for Introversion-Extroversion and Need to Belongingness is moderately significant. This could be because the adolescents were neither completely introverts nor extroverts. Situational variables were affecting these traits. Also, they are not showing a very high Need for Belongingness. This leads one to conclude that Need for Belongingness could be linked to many other personality traits like self esteem, dependency, autonomy, besides Introversion-Extroversion.The difference between Social Networking Intensity and Need to Belongingness is highly significant which means that if a person has high Need for Belongingness he will seek face-to-face personal contacts more and will access Social Networking sites lesser.

Social Networking is not regarded as a medium to completely satisfy the Affiliation and Belongingness Need for the adolescents. Unlike popular belief adolescents are not craving for networking and they do not overtly seek social interactions. Circumstances and experiences have made them moderate in the Introversion-Extroversion dimension. Hence the influence of Social Networking sites is overemphasized for adolescents. The purpose for compulsive users ofSocial Networking sites might be more than an outlet for their extrovert nature and for making new contacts.

\section{REFERENCES}

1. Ong EY, Ang RP, Ho JC, Lim JC, Goh DH, Lee CS, Chua AY. Narcissism, extraversion and adolescents' self-presentation on Facebook. Personal Individ Differences 2011;50(2):1805.

2. Hoffman MA, Levy-Shiff R, Malinski D. Stress and adjustment in the transition to adolescence: Moderating effects of neuroticism and extroversion. J Youth Adolesc 1996;25(2):161-75.

3. Peter J, Valkenburg PM, Schouten AP. Developing a model of adolescent friendship formation on the Internet. CyberPsychol Behav 2005;8(5):423-30.

4. Gomez R, Holmberg K, Bounds J, Fullarton C, Gomez A. Neuroticism and extraversion as predictors of coping styles during early adolescence. Personal Individ Differences 1997;27(1):3-17.

5. Scholte RH, van Aken MA, van Lieshout CF. Adolescent personality factors in self-ratings and peer nominations and their prediction of peer acceptance and peer rejection. $J$ Personal Assess 1997;69(3):534-54.

6. Amichai-Hamburger $Y$, Wainapel G, Fox S. "On the Internet No One Knows I'm an Introvert": Extroversion, Neuroticism, and Internet Interaction. CyberPsychol Behav 2002; 5(2):125-8.

7. Van der Aa N, Overbeek G, Engels RC, Scholte RH, Meerkerk GJ, Van den Eijnden RJ. Daily and compulsive internet use and well-being in adolescence: a diathesis-stress model based on big five personality traits. J Youth Adolesc 2009;38(6):765-76.

8. Ross C, Orr ES, Sisic M, Arseneault JM, Simmering MG, Orr RR. Personality and motivations associated with Facebook use. Comp Human Behav 2009;25(2):578-86.

9. Hamburger YA, Ben-Artzi E. The relationship between extraversion and neuroticism and the different uses of the Internet. Comp Human Behav 2000;16(4):441-9.

10. Ellison NB, Steinfield C, Lampe C. The benefits of Facebook "friends:" Social capital and college students' use of online social network sites. J Computer-Mediated Comm 2007;12(4):1143-68. 
11. Guilford JP, Guilford RB. An analysis of the factors in a typical test of introversionextroversion. J Abnorm Soc Psychol 1934;28(4):377-89.

12. Lee RM, Robbins SB. Measuring belongingness: The Social Connectedness and the Social Assurance scales. J Counsel Psychol 1995;42(2):232-40.

Acknowledgements - Nil

Conflict of Interest - Nil

Funding - Nil. 